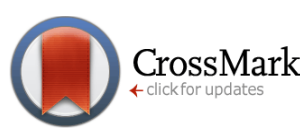

tclickior updates

\title{
Artemisinin-induced delayed hemolysis after administration of artesunate and artesunate-amodiaquine in malaria-free Wistar rats
}

\author{
Titilope M. Dokunmu*, Chidinma L. Ahanonu, \\ Oreoluwa O. Abegunde, Oladipupo A. Adeyemi
}

Biochemistry and Molecular Biology Unit, Biological Sciences Department, Covenant University, Ota, Ogun state, Nigeria

\section{*For correspondence:}

titilope.dokunmu@covenantunivers ity.edu.ng

Competing interests: The authors declare that no competing interests exist.

Received: 28 Feb 2017

Accepted: 12 Arpril 2017

Published: 23 March 2017

Copyright The Author(s) 2017. This article is published with open access by BioMedPress (BMP).

This article is distributed under the terms of the Creative Commons Attribution License (CC-BY 4.0) which permits any use, distribution, and reproduction in any medium, provided the original author(s) and the source are credited.

\section{Abstract}

Background: Hemolysis is common in malaria infection and during the course of treatment. Previous studies have reported delayed post-artemisinin hemolysis occurring in naïve and immune individuals treated with parenteral or oral artemisinin-derivatives. This study aims to understand if delayed hemolysis occurs in the absence of malaria parasites and the underlying mechanisms for the hemolytic effects after administration of two antimalarial drugs to malaria-free Wistar rats. Methods: Forty animals were randomized into 5 groups of eight animals each; they received $4 \mathrm{mg} / \mathrm{kg}$ artesunate for 7 days (AS), $4 \mathrm{mg} / \mathrm{kg}$ artesunate plus $10 \mathrm{mg} / \mathrm{kg}$ amodiaquine for 3 days (ASO), $10 \mathrm{mg} / \mathrm{kg}$ amodiaquine for 3 days (AQ), distilled water [normal control], (Control) and 1mg/kg phenylhydrazine for 1 day to induce hemolysis (PHZ) groups respectively. Packed cell volume (PCV), white blood cell differential count and serum haptoglobin (Hpt) levels were determined in all groups on day 4 and 18 to detect hemolysis. Mean values were compared using t-test and ANOVA with $p$ values $<0.05$ taken to be significantly different. Results: Post-treatment mean PCV on day 4 was significantly lower than day 18 in all groups except AS group which had similar PCV all through evaluation. Although $\mathrm{AO}$ had lowest mean PCV on day 4, by day 18, mean PCV returned to normal and hpt levels was significantly higher than AS and ASO groups ( $p<0.001)$. Hpt level (mean \pm sem) for AS, ASQ, AQ, and control on day 18 were: $18.67 \pm 0.004,50.66 \pm 0.014,73.06$ \pm 0.003 , and $74.13 \pm 0.032 \mathrm{mg} / \mathrm{dl}$ respectively $(p<0.0001)$. On day 18, AS and ASQ had significantly lower Hpt level compared to day $4(p<0.001)$. No neutropenia was observed during the study. Conclusion: Artesunate induces delayed hemolysis in malaria-free animals possibly through an oxidative toxic effect on the red blood cell membrane. Delayed post-treatment hemolysis was not observed with artesunateamodiaquine or amodiaquine alone. 


\section{Keywords}

Antimalarial, Artemisinin, Delayed hemolysis, Drug-induced hemolysis

\section{Introduction}

Hemolysis, the immature destruction of red blood cells (RBC) at a rate that exceeds production of the RBC, commonly occurs in malaria infection. The causes of hemolysis is multifactorial, it may be a consequence of merozoite release from red blood cells, suppression of erythropoiesis by cytokines which are released along with, nutritional deficiencies, immunity, hemoglobinopathies or oxidative effects of drugs. In the food vacuole of malaria parasite, heme increases the activation of the endoperoxide moiety of the drug (Meshnick et al., 1993) to generate reactive oxygen species, glutathione peroxidase and malondialdehyde which causes damage to the parasite membranes and proteins (Meshnick et al., 1989; Scott et al., 1989). The resulting degree of hemolysis depends on the duration and course of malaria infection (Price et al., 2001; Yeo et al., 2009).

Artemisinin based combination treatments are the most rapidly acting and effective antimalarials for treatment of falciparum malaria (WHO, 2013). Artemisinin drugs are known to act by inducing oxidative stress after activation of the peroxide bridge which generates reactive metabolites (Meshnick et al., 1993); this is their major mechanism of killing malaria parasite. Despite generating oxidative radicals, artemsinins are known to conserve the red blood cells, this is demonstrable by moderate falls in hematocrit (Gbotosho et al., 2014; Price et al., 2001) and presence of once infected red blood cells in circulation after parasite clearance (Angus et al., 1997; Chotivanich et al., 2000; Newton et al., 2001). The red cell conservation by artemisinin drugs is however transient because the erythrocytes are eventually destroyed by the spleen leading to the "delayed post-artemisinin hemolytic" syndrome (DPAH).

Delayed hemolysis was first recognized after parenteral artesunate in naïve patients, studies have also reported delayed hemolytic anemia after administration of oral artemisinin derivatives in immune and non-immune subjects with severe malaria or hyperparasitemia (Control and Prevention, 2013; Jauréguiberry et al., 2014; Molta et al., 2003; Rehman et al., 2014; WHO, 2013). Different hypothesis have been proposed to explain the underlying cause of hemolysis after artemisinin treatment, however the hypothesis that pitted erythrocytes are destroyed during recovery best explains post-artesunate delayed hemolysis after treatment of malaria infection (Jauréguiberry et al., 2014). Hemolysis may occur after treatment with different classes of antimalarials 
(Ngole et al., 2010; Price et al., 2001; Sowunmi et al., 2009), however studies have not reported delayed post-treatment hemolysis occurring with antimalarials other than artemisinin derivatives.

This study aims to better understand the mechanism of post-delayed hemolytic effects of artemisinin and a commonly used partner drug - amodiaquine. This study evaluates post-artesunate or ACTs delayed hemolytic effects in uninfected animal model, providing a clear understanding of the mechanism of delayed hemolysis after antimalarial treatment.

\section{Materials - Methods}

\section{Study design}

Forty female albino rats were weighed and divided randomly into five groups of eight animals each. There were 4 treatment groups (3 groups received antimalarials, 1 group received a known hemolytic drug) and one untreated group (control). Treatment outcomes were compared within treatment groups or with positive or normal control group.

\section{Drug treatment}

Two commercially available antimalarials were purchased and used for the study; $200 \mathrm{mg}$ base amodiaquine (Camoquin ${ }$, Pfizer, USA) and 50mg artesunate (Artesunat ${ }^{\circledR}$, Mekophar, Vietnam) and were crushed and dissolved in distilled water. Standard doses of the drugs were administered based on weight of the animals and given orally using cannula. Animals in group 1 received $4 \mathrm{mg} / \mathrm{kg}$ body weight artesunate for 7 days (AS), group 2 received $10 \mathrm{mg} / \mathrm{kg}$ amodiaquine (AQ) for 3 days, group 3 received $4 \mathrm{mg} / \mathrm{kg}$ artesunate plus $10 \mathrm{mg} / \mathrm{kg}$ amodiaquine (ASO) for 3 days, group 4 received distilled water and served as normal control (Control) and group 5 received $1 \mathrm{ml} / \mathrm{kg}$ phenylhydrazine for 1 day and served as positive control for hemolysis (PHZ).

\section{Animals}

The animals were purchased and housed separately per group; they were kept at room temperature in the animal house to acclimatize for one week. They were fed animal feeds ad-libitum and allowed free movement. All the animal experiments and handling were carried out following the standard ethics for Animal studies.

\section{Laboratory tests}

Blood samples for hematological tests were collected by pricking the tail of the rat on day 0,4 or 8 and 18 after treatment. The blood was collected in microhematocrit tubes and centrifuged at $12,000 \times \mathrm{g}$ for 5 minutes to determine 
packed cell volume (PCV). Post-treatment, half of the animals were sacrificed on the day of test; $3 \mathrm{~mL}$ blood was collected through cardiac puncture under mild anesthesia using diethyl ether. The blood samples were collected into heparinized tubes or plain bottles and centrifuged at $12,000 \times \mathrm{g}$ for 15 mins to obtain the serum and plasma. Blood for reticulocyte and white blood cell count was diluted with normal saline and fixed with methanol before counting.

They were stained with Leishman, and counted against 1000 white blood cells using Naubauer hemocytometer under the microscope at magnification of $x 100$. Differential count of the white blood cells was determined by absolute neutrophil, basophil, eosinophil, monocyte and reticulocytes count, thereafter the percentage of each was calculated from a total of 100 cells counted. Haptoglobin test was done on day 4 in half of the animals and on day 18 in the other half. Hemolysis was induced in group 5 by oral administration of $1 \mathrm{ml} / \mathrm{kg}$ body weight of phenylhydrazine intravenously on day 4 . This served as positive control for hemolysis.

\section{Haptoglobin assay}

Rat haptoglobin (Hpt) level was assayed using the biotin labelled ELISA kit (EASTBIOPHARM $®$ ) and was carried out according to manufacturer's instructions as follows. Serum $(40 \mu \mathrm{l})$ sample was added to each Hpt pre-coated well, incubated with anti-Hpt antibody labeled with biotin or streptavidin-HRP at $37^{\circ} \mathrm{C}$ for 60 minutes. The reaction was terminated using chromogen reagent and absorbance was read on a microplate reader at $450 \mathrm{~nm}$ wavelength and compared with standard.

\section{Hematological evaluation}

Hemolytic effects of drug treated groups were compared with normal control and positive control groups. Anemia was taken to be present if PCV value was $<30 \%$ and hemolysis was present if $\mathrm{Hpt}$ level is very low or similar to that of positive control. Overall neutrophil counts lower than 100 (against 1000 WBC) was taken to indicate neutropenia. At recovery phase, hematological values in drug treated groups were compared with control groups to determine extent of hemolysis and recovery.

\section{Statistical Analysis}

The data was analyzed using the SPSS software version 16 (SPSS Inc., Chicago, USA). Graphs were done using excel or Graph pad prism software (Graphpad version 4.0, 1999). Values are reported as mean values \pm standard error of mean or proportions. Mean values were compared using t-test or ANOVA, followed by Duncan's multiple range test, proportions were compared using chi-square test or fisher exact test, the level of significance was set at $p<0.05$. 


\section{Results}

Before treatment, the weight range of the animals was between $170-250 \mathrm{~g}$. The average weight of all animals on day 0 was $201.25 \mathrm{~g}$ and mean packed cell volume on day 0 was $48.1 \%$. Severe hemolytic effects were not recorded in any animal.

\section{Packed cell volume}

Packed cell volume in all but 1 animal was $>30 \%$ prior to treatment, this one animal was excluded from evaluation. Following treatment, anemia was not recorded in any animal. Table 1 shows the hematological outcomes in all groups. Post-treatment and recovery PCV values were similar in AS group ( $p=$ 0.10). In ASQ and AQ groups, there was $28-38 \%$ fall in PCV by day 4 after treatment, this was significantly lower than PHZ group, however mean PCV on day 18 was significantly higher than day 4 ( $p<0.03$ ). In PHZ group, PCV continued to decline until day 18 (Fig. 1). In ASO and AQ, mean PCV on day 4 was significantly lower than other treatment groups ( $p<0.0001)$ (Fig. 1). After completion of treatment, mean PCV was significantly higher in AS than ASO or AQ ( $p<0.0001)$. PCV on day 18 in all groups was similar, but significantly higher than $\mathrm{PHZ}(\mathrm{p}<0.001)$ indicating full recovery from the moderate and non-severe hemolytic effects of the antimalarials.

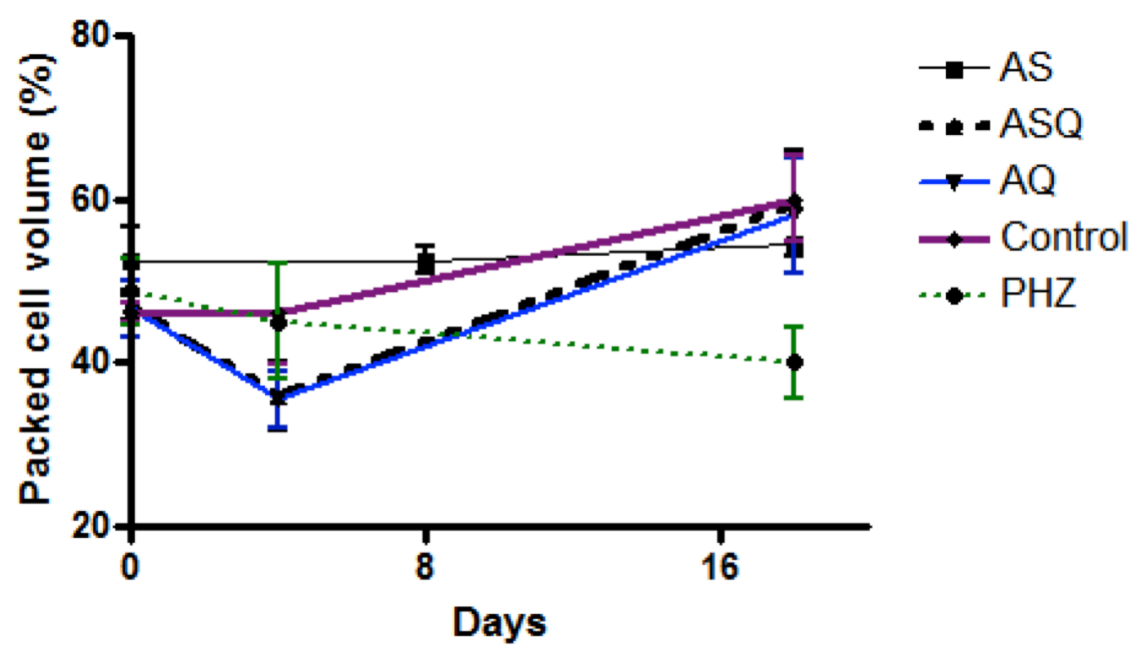

Figure 1. Mean packed cell volume in artesunate (AS), artesunateamodiaquine (ASQ), amodiaquine (AQ), and control (CTRL) groups of malaria-free rats. 


\section{Table 1. Hematological profiles of treated animals during the study}

\begin{tabular}{|c|c|c|c|c|c|c|}
\hline PCV (\%) & AS & ASQ & AQ & $\mathrm{PHZ}$ & Control & $P$ value \\
\hline $\begin{array}{l}\text { D0 } \\
\text { Mean } \pm \text { sd (\%) }\end{array}$ & $52.4 \pm 4.15$ & $46.75 \pm 1.70$ & $47.25 \pm 3.40$ & $48.6 \pm 4.08$ & $46.2 \pm 1.25$ & 0.13 \\
\hline $\begin{array}{l}\text { After treatment } \\
\text { Mean } \pm \text { sd (\%) }\end{array}$ & $52.5 \pm 1.68 \S$ & $36.0 \pm 4.24^{\star}$ & $35.5 \pm 3.50 *$ & $45.0 \pm 7.07$ & $46.0 \pm 6.25$ & $<0.0001$ \\
\hline $\begin{array}{l}\text { At recovery } \\
\text { Mean } \pm \text { sd (\%) }\end{array}$ & $54.5 \pm 0.71$ & $59.5 \pm 6.36$ & $58.0 \pm 7.01$ & $40.0 \pm 4.24^{\star \star}$ & $60.0 \pm 5.25$ & $<0.0001$ \\
\hline $\begin{array}{l}\text { Neutrophil } \\
\text { count D4 (\%) }\end{array}$ & 17 & 16 & 18 & ND & 14 & - \\
\hline $\begin{array}{l}\text { Neutrophil } \\
\text { count D18 (\%) }\end{array}$ & 17 & 19 & 15 & ND & 13 & - \\
\hline $\begin{array}{l}P \text { value } \\
\text { (within group) }\end{array}$ & 0.10 & 0.0001 & 0.001 & 0.56 & 0.003 & - \\
\hline
\end{tabular}

\section{Haptoglobin level}

In AS group, mean Hpt level on day 8 was $67.73 \mathrm{mg} / \mathrm{dl}$, this was significantly higher than Hpt level on day $18(18.67 \mathrm{mg} / \mathrm{dl}), \mathrm{p}<0.0001$. In ASQ, mean Hpt level on day $4(73.06 \mathrm{mg} / \mathrm{dl})$ was significantly higher than day $18(50.66 \pm 0.013$ $\mathrm{mg} / \mathrm{d}), \mathrm{p}=0.001$ while in $\mathrm{AQ}$ group, mean haptoglobin level was significantly lower on day $4(58.13 \mathrm{mg} / \mathrm{dl})$ than day $18(73.46 \mathrm{mg} / \mathrm{dl}), p=0.01$. All treatment groups were compared with control at the recovery phase to determine delayed hemolysis. Hpt level (mean \pm sem) for AS, ASQ, AQ, and control on day 18 were: $18.67 \pm 0.004(n=2), 50.66 \pm 0.014(n=4), 73.06 \pm 0.003(n=4)$, and $74.13 \pm$ $0.032 \mathrm{mg} / \mathrm{dl}(\mathrm{n}=3)$, respectively. There was a significantly lower Hpt level in AS and ASQ groups compared to AQ or control groups on day $18(p<0.05)$ (Fig. 2).

\section{White Blood Cell Differential Count}

Total white blood cell (WBC) count on day 0 was within normal range $\left(5 \times 10^{9} /\right.$ $\mathrm{mm}^{3}$ ), this was similar in all groups at baseline, after treatment (day 4) and during recovery (day 18). Neutrophils were compared within and between groups to determine if neutropenia occurred following treatment and during recovery. Neutropenia and agranulocytosis was not observed. In AS and AQ groups, no significant difference was observed between day 4 and day 18 ( $p=0.703$ ). Overall, there was no significant difference in differential count observed in all groups compared to $\mathrm{PHZ}$ group. 


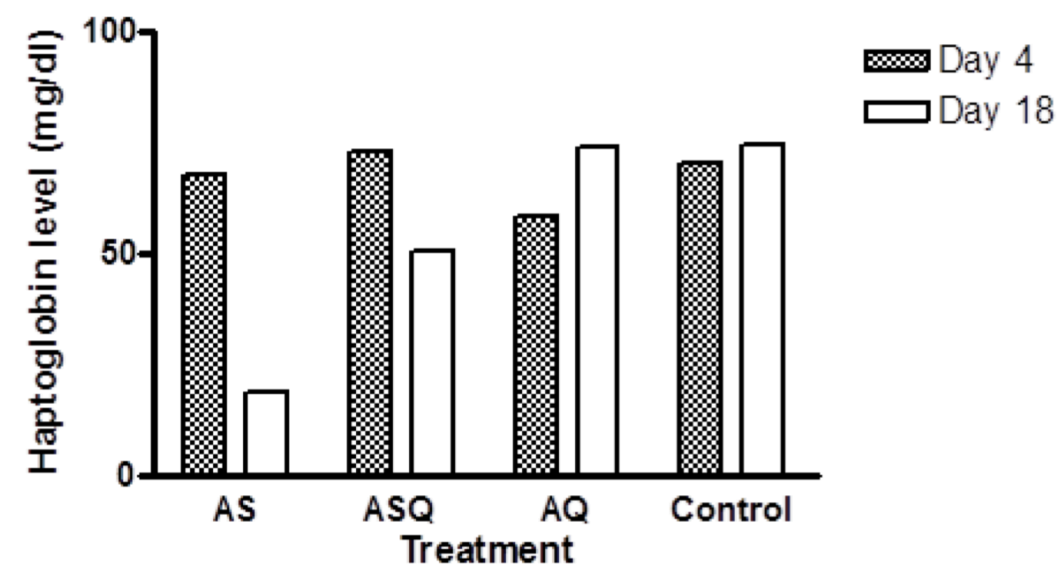

Figure 2. Post-treatment haptoglobin levels in artesunate (AS), artesunateamodiaquine (ASQ), amodiaquine (AQ), and control on day 4 and 18 in malaria-free treated animals.

\section{Discussion}

The recent reports of delayed post-artemisinin hemolysis have brought to light the unrecognized burden of drug-induced hemolysis occurring especially after treatment of infections. Studies have reported immunosuppressive or inhibition of erythropoiesis (Finaurini et al., 2010; Wang et al., 2007; Yang et al., 2005), and other adverse effects of artemisinin derivatives both in the presence or absence of malaria parasites including hemolytic effects (Alzoubi et al., 2014; Anaba et al., 2012; Garba and Ubom, 2005; Gu et al., 1986; Kurth et al., 2016; Lee et al., 2015; Orjih, 1996; Zhou et al., 2005), many of which appear to be non-severe. The mechanism for inducing delayed post-artemisinin hemolysis when administered as monotherapy or co-administered with a partner drug such as amodiaquine remains to be understood. Artemisinin-based combination treatments (ACTs) remains the preferred first-line and safe treatment of falciparum malaria because of its rapid clearance of parasitemia, and reduction of chances of deaths in cases of severe malaria (Sinclair et al., 2012).

In the present study, animals in $A Q$ and $A S O$ groups recovered from the hemolytic effects of all drug treatment. Packed cell volume and differential count by day 18 were similar compared to untreated animals. The lowest PCV values recorded on day 4 (after treatment) is a well explained phenomenon of drug induced hemolysis (Price et al., 2001; Sowunmi et al., 2009). This lends support to findings from other studies reporting decrease in hematocrit level after treatment with ACTs (Gbotosho et al., 2014; Omotuyi, 2008; Price et al., 2001; Rolling et al., 2015). 
After completion of treatment, drug-attributable fall in hematocrit is common, this decline in hematocrit is attributable to the hemolytic effects of longer acting antimalarials (Price et al., 2001; Sowunmi et al., 2009). Haptoglobin is known to facilitate the removal of hemoglobin from the extravascular compartment via the CD163 macrophage scavenger receptor and is usually present in the presence of inflammation, or inflammatory diseases, or hemolysis to block hemoglobininduced oxidative damage by forming haptoglobin-hemoglobin complex with decreased level reported in patients with acute inflammatory disease or hemolysis (Rolling et al., 2015). Reduced serum haptoglobin observed in AS group on day 18 shows hemolysis occurred in the absence of malaria infection, although PCV level appeared normal.

Surprisingly, delayed hemolysis did not occur in ASQ group, this could have been masked by the effects of amodiaquine in the combination. In the absence of malaria parasites, free iron bioactivation of the endoperoxide bridge of artemisinin drugs can be used to modulate its effects (Conran, 2014; Krishna et al., 2004; Meshnick et al., 1989; Meshnick et al., 1993; Muhia et al., 1994; Tangnitipong et al., 2012). Delayed hemolysis in AS group follows a pattern similar to that reported in malaria infected persons (Arguin, 2014; Boillat et al., 2015; Chavada et al., 2015; Conran, 2014; Jauréguiberry et al., 2014; Kurth et al., 2016; Lee et al., 2015; Rehman et al., 2014; Rolling et al., 2015; WHO, 2013), although no anemia was recorded throughout this study.

The mechanism of delayed hemolysis occurring in the absence of malaria parasite is likely due to toxic effects of artemisinin owing to generation of oxidative radicals. This can result in suppression of erythropoiesis (Finaurini et al., 2010; Wang et al., 2007; Yang et al., 2005) and toxicity of the red cell membrane through generation of reactive species which induce oxidative stress causing lipid peroxidation, gluthathione oxidation and oxidation of membrane protein thiols (Meshnick et al., 1993; Scott et al., 1989). Drug-induced oxidative stress worsens hemolysis in the presence of hemoglobinopathies or inadequate protection by the antioxidant defense system of the red blood cells which is often overwhelmed in disease states such as malaria. In the absence of the protective enzyme glucose-6-phosphate dehydrogenase; which maintains the supply of reduced glutathione used to mop up free radicals, oxidative damage of the vascular epithelium occurs (Beutler et al., 2007; Chikezie, 2014). In this study, G6PD deficiency or other hemoglobinopathies cannot be implicated.

Indeed studies have shown that oxidative stress precedes hemolysis of the red blood cells (Jeney et al., 2002; Jollow and McMillan, 2001) following a similar mechanism in both human and rats when exposed to highly oxidative compounds (Vickers et al., 2010). Shortened survival and removal of pitted erythrocytes explains only part of hemolysis in presence of malaria infection (Arguin, 2014; Jauréguiberry et al., 2014; Kurth et al., 2016; Rolling et al., 2015), unparasitized red blood cells are also cleared (Newton et al., 2001). Increased splenic clearance and lysis of the erythrocytes is also attributed to altered symmetry of phospholipid layer and reduced red cell deformability due to 
membrane rigidity caused by merozite invasion (Cooke et al., 2004; Nuchsongsin et al., 2007; Park et al., 2008; Pasvol et al., 1992).

In this study, the haptoglobin levels in all groups were moderately low by day 4, indicating potent hemolytic effect of both artesunate and amodiaquie. Clark et al. (1991) indicated that nitric oxide production increases in a state of infection such as malaria leading to poor deformability of red blood cells membrane (Clark et al., 1991). Free hemoglobin also depletes nitric oxide and increases oxidative inflammatory process. The nitric oxide is thought to inhibit $\mathrm{Na}+\mathrm{K}+$ ATPase and causing oxidization of lipids in the red blood cell membrane through generation of peroxynitrate - a highly potent oxidant (Yeo et al., 2009). Most antimalarials reduce the deformability of the red blood cell membrane which makes the red cell rigid and unable to pass through the microcirculatory bed of the spleen, thus they are marked for splenic clearance (Dondorp et al., 2004).

Drug induced hemolysis can be easily implicated in a case of multiple drug intake, because hemolysis could be triggered via immune complex formation with the drugs on RBC surface or auto-antibody production. In humans, other possible causes of hemolysis include genetic susceptibility such as polymorphisms in drug metabolizing enzymes - CYP2A6 (Roederer et al., 2011), hemoglobinopathies such G-6-P-D deficiency which is common in malaria endemic areas (Beutler et al., 2007; Howes et al., 2012; Price et al., 2001; Van Malderen et al., 2012) and suppressed erythropoiesis after administration of artemisinin, in the presence of other hemolytic factors such as malaria parasite, it would result in anemia as seen in hyperparasitemic individuals.

The hypothesis that explains that post-artemisinin delayed hemolysis after treatment of malaria infection is attributable to eventual destruction of pitted erythrocytes which have a shortened lifespan (Arguin, 2014; Clark, 2014; WHO, 2013) could also explain the case with malaria-free animals in which case exposure to artemisinin drugs cause oxidative stress on the red cell membrane, thus a reduced lifespan or clearance by the spleen. Haptoglobin levels in the experimental animals indicate that hemolysis occurred during treatment in all groups but was more pronounced on day 18 in AS group. Although Hpt level observed in ASO group was low, it was not as low as in artesunate-treated animals on day 18. Only 2 animals were evaluable in AS group on day 18, this may have accounted for a skewed value recorded for the group.

Amodiaquine is implicated as a cause of neutropenia, which is characterized by a decrease in granular white blood cells after prolonged use for prophylaxis (Olliaro and Mussano, 2003). Our findings are in consonance with other reported animals studies (Omotuyi, 2008) and that observed in human treated with amodiaquine, they showed normal limits of hematological profile with no agranulocytosis (Molta et al., 2003). Artesunate have been previously reported to be associated with neutropenia at doses higher than doses administered in our study (Bethell et al., 2010), however neutropenia was not observed with AS, ASO or AQ during the study. This study lends support to a case report of 
artesunate induced auto-immune post-treatment delayed hemolysis, although this occurred in a malaria patient (Raffray et al., 2014).

\title{
Limitations of the study
}

Artesunate treatment was given for 7 days following recommendation for artesunate monotherapy while other treatments were administered for 3 days. This study did not evaluate delayed hemolysis after 3 days administration of artesunate to see if the outcome will differ from the reported result. Other antimalarial drug combinations were not evaluated for this study. Comparison was done in half of the animals in each group sacrificed after treatment and the remaining half at the end of the study. Thus these data were taken to be representative of the hemolytic effects occurring in individual animals. It is not known if this is the case. Lactate dehydrogenase assay was not done and no malaria infected group was evaluated along with the study groups, this group would have shown hemolysis during untreated malaria infection in mice.

\section{Conclusion}

Hemolysis occurred with all treatment in the absence of malaria parasites but rather occurred late; during recovery in AS and ASQ groups, PCV levels did not indicate hemolysis, $>30 \%$ anemia cut off but hpt levels were lower. This study reports that delayed post-artemisinin hemolysis can also occur in the absence of malaria parasites possibly through an oxidative toxic effect on the red blood cell membrane. There was no delayed hemolysis occurring after amodiaquine administration, rather hemolysis occurred immediately after completion of treatment.

\section{Abbreviations}

\author{
ACTs: artemisinin-based combination treatment \\ $\mathrm{AQ}$ : amodiaquine \\ AS: artesunate \\ ASQ: amodiaquine-artesunate \\ ELISA: enzyme-linked immunosorbent assay \\ G6PD: glucose-6-phosphate dehydrogenase \\ Hpt: haptoglobin \\ PCV: packed cell volume \\ RBC: red blood cells
}




\section{Biomedical}

ISSN: $2198-4093$

Research \& Therapy

\section{Acknowledgements}

We thank the Management of Covenant University and Biological Sciences Department for their support during the conduct of the reported study.

\section{Author contribution}

TMD designed the study and wrote the manuscript, AA carried out the laboratory evaluation, all authors participated in the conduct, analysis and contributed to the success of the study. 


\section{References}

Alzoubi, K., Calabrò, S., Bissinger, R., Abed, M., Faggio, C., and Lang, F. (2014). Stimulation of suicidal erythrocyte death by artesunate. Cellular Physiology and Biochemistry 34, 2232-2244.

Anaba, F.C., Ahiante, B.O., and Pepple, D.J. (2012). In vitro hemolytic effect of sulfadoxine/pyrimethamine and artemether/lumefantrine on malaria parasitized erythrocytes of female patients. Pak J Pharm Sci 25, 851-855.

Angus, B.J., Chotivanich, K., Udomsangpetch, R., and White, N.J. (1997). In vivo removal of malaria parasites from red blood cells without their destruction in acute falciparum malaria. Blood 90, 2037-2040.

Arguin, P.M. (2014). Case definition: postartemisinin delayed hemolysis. Blood 124, 157-158.

Bethell, D., Se, Y., Lon, C., Socheat, D., Saunders, D., Teja-lsavadharm, P., Khemawoot, P., Darapiseth, S., Lin, J., and Sriwichai, S. (2010). Dose-dependent risk of neutropenia after 7-day courses of artesunate monotherapy in Cambodian patients with acute Plasmodium falciparum malaria. Clinical Infectious Diseases 51, e105-e114.

Beutler, E., Duparc, S., and Group, G.P.D.W. (2007). Glucose-6-phosphate dehydrogenase deficiency and antimalarial drug development. The American journal of tropical medicine and hygiene 77, 779-789.

Boillat, O., Spechbach, H., Chalandon, Y., and Eperon, G.A. (2015). Post-artesunate delayed haemolysis-report of four cases and review of the literature. Swiss medical weekly 145, w14181.

Chavada, R., Hui, S.H., O'Connor, S., Akima, S., and Gosbell, I. (2015). Post-artesunate delayed haemolysis in severe imported Plasmodium falciparum malaria. The Medical journal of Australia 203, 364-364.

Chikezie, P.C. (2014). Comparative erythrocyte glutathione S-transferase activity profile of Non-malarious guinea pigs (cavia tschudii) administered pyrimethamine/sulfadoxine and artemether/lumefantrine combination therapies. Thrita 3.

Chotivanich, K., Udomsangpetch, R., Dondorp, A., Williams, T., Angus, B., Simpson, J., Pukrittayakamee, S., Looareesuwan, S., Newbold, C., and White, N. (2000). The mechanisms of parasite clearance after antimalarial treatment of Plasmodium falciparum malaria. Journal of Infectious Diseases 182, 629-633.

Clark, I., Rockett, K., and Cowden, W. (1991). Proposed link between cytokines, nitric oxide and human cerebral malaria. Parasitology Today 7, 205-207.

Clark, R.L. (2014). Hypothesized cause of delayed hemolysis associated with intravenous artesunate. Medical hypotheses 82, 167-170.

Conran, N. (2014). Intravascular hemolysis: a disease mechanism not to be ignored. Acta haematologica 132, 97-99.

Control, C.f.D., and Prevention (2013). Published reports of delayed hemolytic anemia after treatment with artesunate for severe malaria--worldwide, 2010-2012. MMWR Morbidity and mortality weekly report 62, 5.

Cooke, B.M., Mohandas, N., and Coppel, R.L. (2004). Malaria and the red blood cell membrane. Paper presented at: Seminars in hematology (Elsevier). 
Dondorp, A.M., Pongponratn, E., and White, N.J. (2004). Reduced microcirculatory flow in severe falciparum malaria: pathophysiology and electron-microscopic pathology. Acta tropica 89, 309-317.

Finaurini, S., Ronzoni, L., Colancecco, A., Cattaneo, A., Cappellini, M.D., Ward, S.A., and Taramelli, D. (2010). Selective toxicity of dihydroartemisinin on human CD34+ erythroid cell differentiation. Toxicology 276, 128-134.

Garba, I., and Ubom, G. (2005). Total serum lactate dehydrogenase activity in acute Plasmodium falciparum malaria infection. Singapore medical journal 46, 632.

Gbotosho, G.O., Okuboyejo, T., Happi, C.T., and Sowunmi, A. (2014). Fall in Hematocrit per 1000 Parasites Cleared From Peripheral Blood: A Simple Method for Estimating Drug-Related Fall in Hematocrit After Treatment of Malaria Infections. American journal of therapeutics 21, 193-197.

Gu, H., Warhurst, D.C., and Peters, W. (1986). Hemolysis induced by artemisinin and its derivatives in vitro. Zhongguo yao li xue bao= Acta pharmacologica Sinica 7, 269.

Howes, R.E., Piel, F.B., Patil, A.P., Nyangiri, O.A., Gething, P.W., Dewi, M., Hogg, M.M., Battle, K.E., Padilla, C.D., and Baird, J.K. (2012). G6PD deficiency prevalence and estimates of affected populations in malaria endemic countries: a geostatistical modelbased map. PLoS Med 9, e1001339.

Jauréguiberry, S., Ndour, P.A., Roussel, C., Ader, F., Safeukui, I., Nguyen, M., Biligui, S., Ciceron, L., Mouri, O., and Kendjo, E. (2014). Postartesunate delayed hemolysis is a predictable event related to the lifesaving effect of artemisinins. Blood 124, 167-175.

Jeney, V., Balla, J., Yachie, A., Varga, Z., Vercellotti, G.M., Eaton, J.W., and Balla, G. (2002). Pro-oxidant and cytotoxic effects of circulating heme. Blood 100, 879-887.

Jollow, D.J., and McMillan, D.C. (2001). Oxidative stress, glucose-6-phosphate dehydrogenase and the red cell. In Biological Reactive Intermediates VI (Springer), pp. 595-605.

Krishna, S., Uhlemann, A.-C., and Haynes, R.K. (2004). Artemisinins: mechanisms of action and potential for resistance. Drug Resistance Updates 7, 233-244.

Kurth, F., Lingscheid, T., Steiner, F., Stegemann, M.S., Bélard, S., Menner, N., Pongratz, P., Kim, J., von Bernuth, H., and Mayer, B. (2016). Hemolysis after Oral Artemisinin Combination Therapy for Uncomplicated Plasmodium falciparum Malaria. Emerging Infectious Diseases 22, 1381.

Lee, J., Krajden, S., Graham, C., Boggild, A.K., Pavenski, K., Keystone, J.S., and Kain, K.C. (2015). Severe delayed hemolysis associated with regulated parenteral antimalarial drug. Emerging infectious diseases 21, 164.

Meshnick, S., Tsang, T., Lin, F., Pan, H., Chang, C., Kuypers, F., Chiu, D., and Lubin, B. (1989). Activated oxygen mediates the antimalarial activity of qinghaosu. Progress in clinical and biological research 313, 95-104.

Meshnick, S.R., Yang, Y., Lima, V., Kuypers, F., Kamchonwongpaisan, S., and Yuthavong, Y. (1993). Iron-dependent free radical generation from the antimalarial agent artemisinin (qinghaosu). Antimicrobial Agents and Chemotherapy 37, 1108-1114.

Molta, N., Oguche, S., Pam, S., Omalu, I., Afolabi, B., Odujoko, J., Amajoh, C., Adeniji, B., Wuyep, V., and Ekanem, O. (2003). Amodiaquine treatment of uncomplicated malaria in children, in an area of chloroquine-resistant Plasmodium falciparum in north-central Nigeria. Annals of Tropical Medicine \& Parasitology 97, 663-669. 
Muhia, D., Thomas, C., Ward, S., Edwards, G., Mberu, E., and Watkins, W. (1994). Ferriprotoporphyrin catalysed decomposition of artemether: analytical and pharmacological implications. Biochemical pharmacology 48, 889-895.

Newton, P.N., Chotivanich, K., Chierakul, W., Ruangveerayuth, R., Teerapong, P., Silamut, K., Looareesuwan, S., and White, N.J. (2001). A comparison of the in vivo kinetics of Plasmodium falciparum ring-infected erythrocyte surface antigen-positive and-negative erythrocytes. Blood 98, 450-457.

Ngole, S.I.U., Theresa, N.-A., Moses, S., Thomas, N., Manka, N.E., and Titanji, V. (2010). Haematological changes and recovery associated with treated and untreated Plasmodium falciparum infection in children in the Mount Cameroon Region. Journal of Clinical Medicine and Research 2, 143-151.

Nuchsongsin, F., Chotivanich, K., Charunwatthana, P., Fausta, O.-S., Taramelli, D., Day, N.P., White, N.J., and Dondorp, A.M. (2007). Effects of malaria heme products on red blood cell deformability. The American journal of tropical medicine and hygiene 77, 617-622.

Olliaro, P.L., and Mussano, P. (2003). Amodiaquine for treating malaria. The Cochrane Library.

Omotuyi, I.O., Nwangwu, S. C., Okugbo, O. T., Okoye, O. T., Ojieh, G. C., and Wogu, D. M. (2008). Hepatotoxic and hemolytic effects of acute exposure of rats to artesunate overdose. African Journal of Biochemistry Research 2, 107-110.

Orjih, A.U. (1996). Haemolysis of Plasmodium falciparum trophozoite-infected erythrocytes after artemisinin exposure. British journal of haematology 92, 324-328.

Park, Y., Diez-Silva, M., Popescu, G., Lykotrafitis, G., Choi, W., Feld, M.S., and Suresh, S. (2008). Refractive index maps and membrane dynamics of human red blood cells parasitized by Plasmodium falciparum. Proceedings of the National Academy of Sciences 105, 13730-13735.

Pasvol, G., Clough, B., and Carlsson, J. (1992). Malaria and the red cell membrane. Blood reviews 6, 183-192.

Price, R.N., Simpson, J.A., Nosten, F., Luxemburger, C., Hkirjaroen, L., ter Kuile, F., Chongsuphajaisiddhi, T., and White, N.J. (2001). Factors contributing to anemia after uncomplicated falciparum malaria. The American journal of tropical medicine and hygiene 65, 614-622.

Raffray, L., Receveur, M.-C., Beguet, M., Lauroua, P., Pistone, T., and Malvy, D. (2014). Severe delayed autoimmune haemolytic anaemia following artesunate administration in severe malaria: a case report. Malaria journal 13, 398.

Rehman, K., Lötsch, F., Kremsner, P.G., and Ramharter, M. (2014). Haemolysis associated with the treatment of malaria with artemisinin derivatives: a systematic review of current evidence. International Journal of Infectious Diseases 29, 268-273.

Roederer, M.W., McLeod, H., and Juliano, J.J. (2011). Can pharmacogenomics improve malaria drug policy? Bulletin of the World Health Organization 89, 838-845.

Rolling, T., Agbenyega, T., Krishna, S., Kremsner, P.G., and Cramer, J.P. (2015). Delayed haemolysis after artesunate treatment of severe malaria-Review of the literature and perspective. Travel medicine and infectious disease 13, 143-149.

Scott, M.D., Meshnick, S.R., Williams, R.A., Chiu, D.T., Pan, H.C., Lubin, B.H., and Kuypers, F.A. (1989). Qinghaosu-mediated oxidation in normal and abnormal erythrocytes. The Journal of laboratory and clinical medicine 114, 401-406. 
Sinclair, D., Donegan, S., Isba, R., and Lalloo, D.G. (2012). Artesunate versus quinine for treating severe malaria. Cochrane Database Syst Rev 6.

Sowunmi, A., Gbotosho, G.O., Happi, C., Okuboyejo, T., Folarin, O., Balogun, S., and Michael, O. (2009). Therapeutic efficacy and effects of artesunate-mefloquine and mefloquine alone on malaria-associated anemia in children with uncomplicated Plasmodium falciparum malaria in southwest Nigeria. The American journal of tropical medicine and hygiene 81, 979-986.

Tangnitipong, S., Thaptimthong, T., Srihirun, S., Unchern, S., Kittikool, D., Udomsangpetch, R., and Sibmooh, N. (2012). Extracellular heme enhances the antimalarial activity of artemisinin. Biological and Pharmaceutical Bulletin 35, 29-33.

Van Malderen, C., Van Geertruyden, J.-P., Machevo, S., González, R., Bassat, Q., Talisuna, A., Yeka, A., Nabasumba, C., Piola, P., and Daniel, A. (2012). Glucose-6phosphate dehydrogenase deficiency, chlorproguanil-dapsone with artesunate and posttreatment haemolysis in African children treated for uncomplicated malaria. Malaria journal 11, 139.

Vickers, A.E., Sinclair, J.R., Fisher, R.L., Morris, S.R., and Way, W. (2010). Blood cell oxidative stress precedes hemolysis in whole blood-liver slice co-cultures of rat, dog, and human tissues. Toxicology and applied pharmacology 244, 354-365.

Wang, J.X., Tang, W., Shi, L.P., Wan, J., Zhou, R., Ni, J., Fu, Y.F., Yang, Y.F., Li, Y., and Zuo, J.P. (2007). Investigation of the immunosuppressive activity of artemether on T-cell activation and proliferation. British journal of pharmacology 150, 652-661.

WHO (2013). World Health Organization (2013). WHO Information Note on Delayed Haemolytic Anaemia following Treatment with Artesunate. WHO/GMP Information Note, October 2, 2013.

Yang, Z.S., Zhou, W.L., Sui, Y., Wang, J.X., Wu, J.M., Zhou, Y., Zhang, Y., He, P.L., Han, J.Y., Tang, W., et al. (2005). Synthesis and immunosuppressive activity of new artemisinin derivatives. 1. [12(beta or alpha)-Dihydroartemisininoxy]phen(ox)yl aliphatic acids and esters. Journal of medicinal chemistry 48, 4608-4617.

Yeo, T.W., Lampah, D.A., Tjitra, E., Gitawati, R., Kenangalem, E., Piera, K., Granger, D.L., Lopansri, B.K., Weinberg, J.B., and Price, R.N. (2009). Relationship of cell-free hemoglobin to impaired endothelial nitric oxide bioavailability and perfusion in severe falciparum malaria. Journal of Infectious Diseases 200, 1522-1529.

Zhou, W.L., Wu, J.M., Wu, Q.L., Wang, J.X., Zhou, Y., Zhou, R., He, P.L., Li, X.Y., Yang, Y.F., Zhang, Y., et al. (2005). A novel artemisinin derivative, 3-(12-beta-artemisininoxy) phenoxyl succinic acid (SM735), mediates immunosuppressive effects in vitro and in vivo. Acta pharmacologica Sinica 26, 1352-1358. 